Gut and Liver, Vol. 10, No. 4, July 2016, pp. 493-494

\title{
Proton Pump Inhibitors Should be Used with Caution in Critically III Patients to Prevent the Risk of Clostridium difficile Infection
}

\author{
Jung Hwa Min and You Sun Kim \\ Department of Internal Medicine, Seoul Paik Hospital, Inje University College of Medicine, Seoul, Korea
}

See "Risk of Clostridium difficile Infection with the Use of a Proton Pump Inhibitor for Stress Ulcer Prophylaxis in Critically III Patients" by Youngouk Ro, et al. on page 581, Vol. 10. No. 4, 2016

The incidence and severity of Clostridium difficile infection (CDI), which is the most important cause of nosocomial diarrhea, have increased globally. ${ }^{1-4}$ In North America and Europe, CDI has been well established for decades, becoming a particular issue after $2000 .{ }^{1}$ A recent nationwide study conducted in South Korea involving 17 hospitals indicated that the incidence of CDI is significantly increasing, from 1.7 cases/1,000 adult admissions in 2004 to 2.7 cases/1,000 adult admissions in 2008 $(\mathrm{p}=0.028)^{2}$ In addition, the recurrence of CDI after successful treatment is observed in approximately $20 \%$ of patients. ${ }^{5}$ Therefore, even in Asia, the emergence and considerable burden associated with CDI should not be underestimated.

It is assumed that both the appearance of hypervirulent strains (e.g., BI/NAP1/ribotype 027) and impaired host immune status are responsible for this increase in CDI incidence. ${ }^{1}$ The most important risk factor for CDI is the use of broad-spectrum antibiotics, and other well-known risk factors include older age, prolonged hospitalization, and severe underlying disease, as well as enteral feeding and acid suppression therapy. ${ }^{1,6,7}$

Acid suppression therapy, such as that with proton pump inhibitors (PPIs) and histamine 2 receptor antagonists ( $\left.\mathrm{H}_{2} \mathrm{RAs}\right)$, is widely used in critically ill patients to prevent stress ulcers. Maintenance of intragastric $\mathrm{pH} \geq 3.5$ using these agents prevents gastric mucosal injury, and PPIs seem to be more effective than $\mathrm{H}_{2}$ RAs for preventing clinically meaningful gastrointestinal bleeding. ${ }^{8}$ However, the wide use of PPIs could be related with several adverse effects, such as fractures and hypomagnesemia, ${ }^{9}$ although the underlying mechanisms remain uncertain. In addition, the loss of the acidic environment in the stomach caused by PPIs could lead to inadequate sterilization of ingested organisms such as C. difficile. Moreover, acid suppression may weaken the defense against ingested $C$. difficile and increase the risk of $C$. difficile colonization.

Two recent meta-analyses with large sample sizes analyzed the association between CDI and PPI therapy. The first study by Janarthanan et al. ${ }^{6}$ included 17 case-control and six cohort studies with a total of 288,620 participants and reported a relative risk (RR) of CDI of 1.69 (95\% confidence interval [CI], 1.40 to 1.97 ), and the second study by Kwok et al. ${ }^{7}$ included 30 casecontrol and 12 cohort studies with a total of 313,000 participants and reported a pooled odds ratio (OR) of 1.74 (95\% CI, 1.47 to 2.85) for CDI among PPI users. These results suggest that PPI use is associated with an increased risk of CDI, although both the RR and OR were less than two times. This weak association between acid suppression therapy and CDI is responsible for the contrary result of other study that use of PPIs has no effect on the development of CDI. ${ }^{10}$

In this issue, Ro et al. ${ }^{11}$ reported an incidence of CDI of 3.8\% $(38 / 1,005)$ in patients who received stress ulcer prophylaxis (SUP) therapy in the intensive care unit (ICU). The incidence of SUPrelated CDI was considerably higher in patients who received PPIs than in those who received $\mathrm{H}_{2}$ RAs (6.7\% vs $1.8 \%$ ), and PPI use was an independent risk factor for SUP-related CDI (OR, 3.3; 95\% CI, 1.5 to $7.1 ; p=0.003$ ). Despite the limitations of a retrospective design, relatively small sample size, and analysis limited to only part of the hospitalization period, the results are very meaningful in terms of the increased risk for CDI with PPI use (OR, 3.3) in a high-risk group of critically ill patients with severe underlying diseases (i.e., those in the ICU), compared with that in the general population $(\mathrm{OR}, 1.7)$. These results indicated

Correspondence to: You Sun Kim

Department of Internal Medicine, Seoul Paik Hospital, Inje University College of Medicine, 9 Mareunnae-ro, Jung-gu, Seoul 04551, Korea

Tel: +82-2-2270-0012, Fax: +82-2-2270-0257, E-mail: yousunk69@korea.com

pISSN 1976-2283 eISSN 2005-1212 http://dx.doi.org/10.5009/gnl16216

@) This is an Open Access article distributed under the terms of the Creative Commons Attribution Non-Commercial License (http://creativecommons.org/licenses/by-nc/4.0) which permits unrestricted non-commercial use, distribution, and reproduction in any medium, provided the original work is properly cited. 
that the risk of CDI could be intensified when the risk factors are combined. That means even the risk of PPIs use is not high for the development of CDI, if the patients have the other risk of $\mathrm{CDI}$, the risk of PPIs use for CDI could be increased.

CDI is basically a nosocomial infection, and the preventive strategies against CDI, including hand washing and proper isolation, are important for the medical environment. In addition, clinicians should be cautious when prescribing broad-spectrum antibiotics as well as PPIs, especially for critically ill patients, considering the possibility of CDI.

\section{CONFLICTS OF INTEREST}

No potential conflict of interest relevant to this article was reported.

\section{REFERENCES}

1. Burke KE, Lamont JT. Clostridium difficile infection: a worldwide disease. Gut Liver 2014;8:1-6.

2. Kim YS, Han DS, Kim YH, et al. Incidence and clinical features of Clostridium difficile infection in Korea: a nationwide study. Epidemiol Infect 2013;141:189-194.

3. Pépin J, Valiquette L, Alary ME, et al. Clostridium difficile-associated diarrhea in a region of Quebec from 1991 to 2003: a changing pattern of disease severity. CMAJ 2004;171:466-472.

4. Gweon TG, Lee KJ, Kang DH, et al. A case of toxic megacolon caused by clostridium difficile infection and treated with fecal microbiota transplantation. Gut Liver 2015;9:247-250.

5. Doh YS, Kim YS, Jung HJ, et al. Long-term clinical outcome of Clostridium difficile infection in hospitalized patients: a single center study. Intest Res 2014;12:299-305.

6. Janarthanan S, Ditah I, Adler DG, Ehrinpreis MN. Clostridium difficile-associated diarrhea and proton pump inhibitor therapy: a meta-analysis. Am J Gastroenterol 2012;107:1001-1010.

7. Kwok CS, Arthur AK, Anibueze CI, Singh S, Cavallazzi R, Loke YK. Risk of Clostridium difficile infection with acid suppressing drugs and antibiotics: meta-analysis. Am J Gastroenterol 2012;107:10111019.

8. Alhazzani W, Alenezi F, Jaeschke RZ, Moayyedi P, Cook DJ. Proton pump inhibitors versus histamine 2 receptor antagonists for stress ulcer prophylaxis in critically ill patients: a systematic review and meta-analysis. Crit Care Med 2013;41:693-705.

9. Atkinson NS, Reynolds DJ, Travis SP. 'Lemonade legs': why do some patients get profound hypomagnesaemia on proton-pump inhibitors? Intest Res 2015;13:227-232.

10. Pepin J, Saheb N, Coulombe MA, et al. Emergence of fluoroquinolones as the predominant risk factor for Clostridium difficileassociated diarrhea: a cohort study during an epidemic in Quebec. Clin Infect Dis 2005;41:1254-1260.

11. Ro Y, Eun CS, Kim HS, et al. Risk of Clostridium difficile infection with the use of a proton pump inhibitor for stress ulcer prophylaxis in critically ill patients. Gut Liver 2016;10:581-586. 